\title{
SYNTHESIS OF NONLINEAR ALGORITHMS FOR MULTIMODE CONTROL OF TRANSPORT ENTERPRISES IN AN INDETERMINATE STATE
}

\author{
Denis Zubenko \\ Department of electric transport \\ Kharkiv National University of Municipal Economy named after Beketov \\ 12 Revolution str., Kharkov, Ukraine, 61000 \\ Denis04@ukr.net \\ Alexsandr Petrenko \\ Department of electric transport \\ Kharkiv National University of Municipal Economy named after Beketov \\ 12 Revolution str., Kharkov, Ukraine, 61000 \\ Petersanya2007@mail.ru
}

\begin{abstract}
Modern living conditions and growing uncertainties in the decision in choosing strategy conduct for transport enterprises, define the trend to create automatic systems of decision-making and forecasting. The fundamental and powerful argument for the creation of fuzzy logic systems is the reduction of costs (resource consumption) now as a result of economic and technological activities. Rational use of resources now depends on the basic performance management system. The proposed methods of information processing in the existing algorithms cannot solve this problem in its entirety, so synthesis proposed new algorithms and approaches that are used to build neural networks, with the possibility of learning.

In this article we consider the problem of synthesis of nonlinear algorithms for multi-mode process control (transport company) in the state space. A new algorithmic approach to the synthesis of the non-linear multi-mode controller for TP (transport companies), the disclosure of which is given in the form of a set of linear models is presented. At the executive management level to ensure solved the problem of maintaining high-precision settings to (dynamically changing object) with given constraints on the dynamic characteristics of the system. For example, TP, these restrictions are related to ensuring high reliability of functioning of the ACS (automatic control system). Design decisions at the executive level of the synthesis process control algorithms are implemented on the basis of algorithms that satisfy the principle of minimal complexity.

A characteristic feature of the search task of project solutions at the executive level is the need to take account of the nonlinear nature of the work of TP in different modes of operation, which significantly complicates the problem of defining the optimal solution.
\end{abstract}

Keywords: transport companies, control systems, fuzzy logic, neural networks, control algorithms.

(C) Denis Zubenko, Alexsandr Petrenko

\section{Introduction}

Consider the features of the information model of executive-level automation systems (information transport enterprise management system), which reflect the characteristics of the information flows at the executive level of the TA. The generalized information model can be simplified, taking into account the assumption that changes depending on the TP parameters on environmental parameters.

\section{Materials and Methods}

In [1-3] it is stated that the method of decentralized management is widely spread in the management of multidimensional nonlinear objects. Thus ACS is divided into a number of individual (autonomous) subsystems, each of which performs a particular measurement position controlled. Compare it with the setpoint (command) and the production of the control action, coming on to the appropriate input. 


\section{Experimental procedures}

In the classical formulation of the control synthesis problem in the state space for a linear system it is assumed that given the controlled linear system with constant coefficients

$$
\begin{gathered}
\dot{x}=A x+b u, \\
\dot{x}=A x+b^{T} x=\left(A+b k^{T}\right) x,
\end{gathered}
$$

the roots of the characteristic equation $\operatorname{det}\left|\mathrm{A}+\mathrm{bk}^{\mathrm{T}}-\lambda \mathrm{E}\right|=0$, appeared equal to specified numbers $\{\lambda\}$.

If you use linear transducers for the linear system of differential equations $\mathrm{x}=\mathrm{My}$, $\mathrm{M}=\left(\mathrm{m}_{1, \ldots \ldots . .} \mathrm{m}_{\mathrm{n}}\right),\left(\mathrm{m}_{\mathrm{i}}-\right.$ eigenvector $)$, the solution will have the form

$$
\mathrm{x}=\mathrm{M}\left(\exp \operatorname{diag}(\lambda) \mathrm{M}^{-1} \mathrm{x}_{0}=(\exp A t) \mathrm{x}_{0} .\right.
$$

For non-linear systems of the form

$$
\dot{x}=X(x)=A(x) x .
$$

By analogy with the linear systems we can write the equation for the eigenvalues and eigenvectors as follows:

$$
\mathrm{A}(\mathrm{x}) \mathrm{m}_{\mathrm{S}}(\mathrm{x})=\lambda(\mathrm{x}) \mathrm{m}_{\mathrm{s}}(\mathrm{x}), \quad \mathrm{s}=1+\mathrm{n} .
$$

Substitute non-linear transformation $\mathrm{x}=\mathrm{M}(\mathrm{x}) \mathrm{y}$, where $\mathrm{M}(\mathrm{x})=\left(\mathrm{m}_{1}(\mathrm{x}), \mathrm{m}_{2}(\mathrm{x}), \ldots \ldots, \mathrm{m}_{\mathrm{N}}(\mathrm{x})\right)$ in (5) we get

$$
M(x) y+M(x) y=A(x) M(x) y
$$

From (6) we find a solution in the form

$$
\mathrm{y}^{\prime}=\mathrm{M}^{-1}(\mathrm{x}) \mathrm{M}(\mathrm{x}) \mathrm{y}^{\prime}=\mathrm{A}(\mathrm{x}) \mathrm{M}^{-1}(\mathrm{x}) \mathrm{y} .
$$

Because the term $\mathrm{M}^{-1}(\mathrm{x}) \mathrm{M}(\mathrm{x}) \mathrm{y}$ in (7) impermissible judgment about the stability of the system (4) only the roots of the characteristic equation

$$
\operatorname{det}(\mathrm{A}(\mathrm{x})-\lambda(\mathrm{x}) \mathrm{E})=0,
$$

as in equation (7) the matrix $\mathrm{M}^{-1}(\mathrm{x}) \mathrm{M}(\mathrm{x}) \mathrm{y}^{\prime} \neq 0$.

If $\lambda_{\mathrm{r}}=\lambda_{\mathrm{S}}(\mathrm{x})$ for $\mathrm{A}(\mathrm{x})$, but $\mathrm{m}_{\mathrm{s}}=$ const, $\mathrm{s}=1 \div \mathrm{n}$, i-n, those. matrix $\mathrm{M}(\mathrm{x})$ It is made up of permanent and vectors $\mathrm{M}(\mathrm{x})=0$, then the solution of the system (4) can be represented as follows:

$$
\mathrm{x}=\mathrm{x}_{0} \exp \int_{\mathrm{t}}^{\mathrm{t}} \mathrm{A}(\mathrm{x}) \mathrm{d} \tau \text {. }
$$

\section{1. Synthesis of nonlinear ACS TP specified point-linear models}

In the first stage of the conditions specified accuracy approximation TP characteristics formed the set of linear dynamic models; describe the dynamic properties of the TA for small deviations of controlled origin in the vicinity of $\mathrm{N}$ modes. Each (i-I) Linear Model TP is as follows:

$$
\begin{aligned}
& x=A_{1} x+B_{i} x, \\
& y=C_{1} x+D_{i} u .
\end{aligned}
$$


On the second and third stage for a variety of linear models (9) the condition of controllability of eigenvectors and eigenvalues is checked, given the following identity [4-6]:

$$
\left(\mathrm{B}_{\mathrm{i}} \mathrm{B}_{\mathrm{i}}^{+}-\mathrm{E}\right)\left(\mathrm{M}_{\lambda} \operatorname{diag}(\lambda)_{\mathrm{i}}-\mathrm{A}_{\mathrm{i}} \mathrm{M}_{\pi \lambda}\right)=0,
$$

where $B^{+}=\left(B_{i} B\right)^{-1} B^{\tau}-$ matrix

\section{2. The entropy of the environment}

The measure of uncertainty of the environment state can be estimated as follows:

$$
H(F)=-\int_{U f} p(F) I n p(F) d F .
$$

\section{3. The algorithm synthesis of nonlinear ACS TP defined nonlinear polynomial models}

Let the nonlinear ACS TP is be described as follows

$$
\mathrm{dx} / \mathrm{dt}=\mathrm{Ax}+\mathrm{H}(\mathrm{x})+\mathrm{Bu}(\mathrm{x})
$$

the members of non-linear systems are uniform.

Consider the search task management solution $\mathrm{u}(\mathrm{x})$. Set up a system of equations for the eigenvectors and eigenvalues of the linear and nonlinear parts of the system (12) based on control and condition (12)

$$
\begin{aligned}
& \lambda_{\mathrm{s}} \mathrm{m}_{\mathrm{s}}=\left(\mathrm{A}+\mathrm{Bk}^{\mathrm{T}}\right) \mathrm{m}, \\
& \rho_{\mathrm{s}} \mathrm{m}_{\mathrm{s}}=\mathrm{H}\left(\mathrm{m}_{\mathrm{s}}\right)+\mathrm{BU}\left(\mathrm{m}_{\mathrm{s}}\right) .
\end{aligned}
$$

Rewrite system (7) as a non-linear system of equations:

$$
\begin{aligned}
& \lambda \mathrm{m}_{1}=\mathrm{a}_{11} \mathrm{~m}_{1}+\ldots . .+\mathrm{a}_{1 \mathrm{n}} \mathrm{m}_{\mathrm{n}}+\mathrm{b}_{1} \mathrm{k}_{1} \mathrm{~m}_{1}+\ldots . .+\mathrm{b}_{1} \mathrm{k}_{\mathrm{n}} \mathrm{m}_{\mathrm{n}}, \\
& \lambda \mathrm{m}_{1}=\mathrm{a}_{\mathrm{n} 1} \mathrm{~m}_{\mathrm{n}}+\ldots . .+\mathrm{a}_{\mathrm{nn}} \mathrm{m}_{\mathrm{n}}+\mathrm{b}_{\mathrm{n}} \mathrm{k}_{1} \mathrm{~m}_{1}+\ldots . .+\mathrm{b}_{\mathrm{n}} \mathrm{k}_{\mathrm{n}} \mathrm{m}_{\mathrm{n}} .
\end{aligned}
$$

The system (14) can be represented as follows

$$
\mathrm{B}(\lambda, \mathrm{k}) \mathrm{m}=0
$$

where $\mathrm{B}(\lambda, \mathrm{k})$ is the square symbolic matrix, the determinant $\mathrm{P}$ is equal to

$$
\mathrm{P}=\operatorname{det}(\mathrm{B}(\lambda, \mathrm{k}))=\mathrm{C}_{\mathrm{n}}(\mathrm{k}) \lambda^{\mathrm{n}}+\mathrm{C}_{\mathrm{n}}(\mathrm{k}) \lambda^{\mathrm{n}-1}+\ldots \ldots \mathrm{C}_{0}(\mathrm{k})=0 .
$$

For the system (14), taking into account the conditions (16) set up a system of equations.

$$
\begin{aligned}
& \lambda_{\mathrm{s}} \mathrm{m}_{\mathrm{s} 1}=-2 \mathrm{~m}_{\mathrm{s} 1}+\mathrm{m}_{\mathrm{s} 2}+\mathrm{k}_{1} \mathrm{~m}_{\mathrm{s} 1}+\mathrm{k}_{2} \mathrm{~m}_{2} ; \\
& \lambda_{\mathrm{s}} \mathrm{m}_{\mathrm{s} 1}=-\mathrm{m}_{\mathrm{s} 2}+2 \mathrm{k}_{1} \mathrm{~m}_{\mathrm{s} 1}+2 \mathrm{k}_{2} \mathrm{~m}_{2} ; \\
& \mathrm{p}_{\mathrm{s}} \mathrm{m}_{\mathrm{s} 1}=\mathrm{m}_{\mathrm{s} 2}^{2} ; \\
& \mathrm{p}_{\mathrm{s}} \mathrm{m}_{\mathrm{s} 2}=-\mathrm{m}_{\mathrm{s} 1}^{2},
\end{aligned}
$$

excluding $\mathrm{P}_{\mathrm{s}}$, rewrite (17) as follows

$$
\begin{aligned}
& \mathrm{f}_{1}=\left(\lambda_{\mathrm{s}}+2-\mathrm{k}_{1}\right) \mathrm{m}_{\mathrm{s} 1}+\left(-1-\mathrm{k}_{2}\right) \mathrm{m}_{\mathrm{s} 2}=0 ; \\
& \mathrm{f}_{2}=-2 \mathrm{k}_{1} \mathrm{~m}_{\mathrm{s} 1}+\left(\lambda_{\mathrm{s}}-1-\mathrm{k}_{2}\right) \mathrm{m}_{\mathrm{s} 2}=0 ; \\
& \mathrm{f}_{3}=\mathrm{m}^{2}{ }_{\mathrm{s} 1}+\mathrm{m}_{\mathrm{s} 2}^{3}=0 .
\end{aligned}
$$


We use the following notation

$$
\begin{aligned}
& \mathrm{a}_{1}=\lambda_{\mathrm{s}}+2-\mathrm{k}_{1}, \mathrm{a}_{2}=-1-\mathrm{k}_{2} ; \\
& \mathrm{a}_{3}=-2 \mathrm{k}_{1}, \mathrm{a}_{2}=\lambda_{\mathrm{s}}-1-2 \mathrm{k}_{2} .
\end{aligned}
$$

Next to $F=\left\{\mathrm{f}_{1}, \mathrm{f}_{2}, \mathrm{f}_{3}\right\}$ we construct a Gröbner basis

$$
\begin{aligned}
& \mathrm{S}_{\mathrm{p}}\left(\mathrm{f}_{1} \mathrm{f}_{3}\right)=\mathrm{m}_{\mathrm{s} 1}^{2} \mathrm{f}_{1}-\mathrm{a}_{1} \mathrm{f}_{3}=\mathrm{a}_{2} \mathrm{~m}_{\mathrm{s} 1}^{2}-\mathrm{a}_{1} \mathrm{~m}_{\mathrm{s} 2}^{2}=\mathrm{f}_{4}=0 ; \\
& \mathrm{S}_{\mathrm{p}}\left(\mathrm{f}_{2} \mathrm{f}_{4}\right)=\mathrm{a}_{2} \mathrm{~m}_{\mathrm{s} 1} \mathrm{f}_{2}-\mathrm{a}_{3} \mathrm{f}_{4}=\mathrm{a}_{2} \mathrm{a}_{4} \mathrm{~m}_{\mathrm{s} 1}-\mathrm{a}_{1} \mathrm{a}_{2} \mathrm{a}_{3}=\mathrm{f}_{5}=0 ; \\
& \mathrm{S}_{\mathrm{p}}\left(\mathrm{f}_{2} \mathrm{f}_{5}\right)=\mathrm{a}_{2} \mathrm{a}_{4} \mathrm{f}_{2}-\mathrm{a}_{3} \mathrm{f}_{5}=\mathrm{m}_{\mathrm{s} 2}\left(\mathrm{a}_{2} \mathrm{a}^{2}{ }_{4}-\mathrm{a}_{1} \mathrm{a}_{3}{ }_{3}\right)=\mathrm{f}_{6}=0 .
\end{aligned}
$$

From (19) we choose a polynomial

$$
\mathrm{f}_{6}=\mathrm{f}\left(\lambda_{\mathrm{s}}, \mathrm{k}\right)=0 .
$$

Substituting (18) in (20), we obtain the equation

$$
\mathrm{S}(\lambda, \mathrm{k})=-\left(1-\mathrm{k}_{2}\right)\left(\lambda-1-2 \mathrm{k}_{2}\right)^{2}+\left(\lambda+1-\mathrm{k}_{1}\right) 4 \mathrm{k}_{1}^{2}=0 .
$$

Substituting in (21) the desired values of the eigenvalues of the system $\lambda_{1,2}=-2 \pm 3^{-0,5} \mathrm{i}$, find the values of the elements of the vector control

$$
\mathrm{k}_{1} 1 / 2 \mathrm{k}_{2}=-5 / 3 \text {. }
$$

It follows from the above example; it was possible to find a linear control for the nonlinear transformer substation, which provides the required quality management processes throughout the range of operation of the control object.

\section{Results}

As a result of introducing the system in the form of a nonlinear system of equations of the form:

$$
\begin{aligned}
& \mathrm{px}_{1}-\mathrm{a}_{11} \mathrm{x}_{1}-\mathrm{a}_{12} \mathrm{x}_{2}-\ldots . \mathrm{a}_{1 \mathrm{n}} \mathrm{x}_{\mathrm{n}}-\mathrm{b}_{11} \mathrm{u}_{1}-\ldots-\mathrm{b}_{1 \mathrm{~m}} \mathrm{u}_{\mathrm{m}}=0 \\
& \mathrm{px}_{\mathrm{n}}-\mathrm{a}_{\mathrm{n} 1} \mathrm{x}_{1}-\mathrm{a}_{\mathrm{n} 2} \mathrm{x}_{2}-\ldots-\mathrm{a}_{\mathrm{nn}} \mathrm{x}_{\mathrm{n}}-\mathrm{b}_{\mathrm{n} 1} \mathrm{u}_{1}-\ldots-\mathrm{b}_{\mathrm{mm}} \mathrm{u}_{\mathrm{m}}=0 \\
& \mathrm{y}_{1}-\mathrm{c}_{11} \mathrm{x}_{1}-\ldots . \mathrm{c}_{1 \mathrm{n}} \mathrm{x}_{\mathrm{n}}-\mathrm{d}_{11 \mathrm{n}} \mathrm{u}_{1}-\ldots-\mathrm{b}_{1 \mathrm{~m}} \mathrm{u}_{\mathrm{m}}=0 \\
& \mathrm{y}_{\mathrm{k}}-\mathrm{c}_{1 \mathrm{k}} \mathrm{x}_{1}-\ldots . \mathrm{c}_{\mathrm{k} 1 \mathrm{n}} \mathrm{x}_{\mathrm{n}}-\mathrm{d}_{\mathrm{kn}} \mathrm{u}_{1}-\ldots-\mathrm{b}_{\mathrm{km}} \mathrm{u}_{\mathrm{m}}=0
\end{aligned}
$$

\section{Discussion}

As a non-linear model we obtain a piecewise linear model of the following form [7-10]:

$$
\begin{aligned}
& \mathrm{x}=\mathrm{A}_{\mathrm{i}}\left(\mathrm{x}-\mathrm{x}_{\mathrm{i}}^{\mathrm{cm}}\right)+\mathrm{B}_{\mathrm{i}}\left(\mathrm{u}-\mathrm{u}_{\mathrm{i}}^{\mathrm{cm}}\right), \\
& \mathrm{y}=\mathrm{y}_{\mathrm{i}}^{\mathrm{cm}}+\mathrm{C}_{\mathrm{i}}\left(\mathrm{x}-\mathrm{x}_{\mathrm{i}}^{\mathrm{cm}}\right)+\mathrm{D}_{\mathrm{i}}\left(\mathrm{u}-\mathrm{u}_{\mathrm{i}}^{\mathrm{cm}}\right),
\end{aligned}
$$

where $y_{i}^{c m}, x_{i}^{c m}, u_{i}^{c m}$ - values of static characteristics $i-x$ operating points, $i=1 / s$.

\section{Conclusions}

The analysis suggests the following conclusions:

1. A model of executive-level information ACS TP in order to assess the complexity of the information at this level of control algorithms.

2. A method of synthesis of nonlinear ACS TP defined piecewise linear models, using constant eigenvectors, allowing to provide the desired quality of regulation in the partial pickup modes. This 
approach allows the use of different approaches to the synthesis of linear regulators with the additional condition of constancy of the matrix of the canonical basis of a closed system.

3. The criterion of control for nonlinear systems with homogeneous right-hand sides.

\section{References}

[1] Ahmetghaleev I. I. (2014). Eigenvectors and systems stability. The Lyapunov functions and applications, P. Bome and V. Matrosov (editors), J. C. Baltzer AG, Scientific Publishing Co., IMACS, 45-49.

[2] Buchberger B. (2013). An algorithms for finding a basis for the residue class ring of a zerodimensional polynomial ideal (in German). Ph. D. Thesis, Univ Innsbruck.

[3] Chipperfield, A. J., Fleming, P. J. (2014). Systems integration using evolutionary algorithms. Proc. Of the UKACC International Conference on CONTROL September, England, 705-710.

[4] Galushkin, A. I. (2015). Supercomputers and Neurocomputers. Neural Information Processing: Proceedings of the 8"' International Conference: China, Shanghai. November, 14-18, Vol. 3, 1231-1236.

[5] Mclnroy, J. E., Saridis, G. N. (2013). Reliability-Based Control and Sensing Design for Intelligent Machines // in: Reliability Analysis. Ed, J. H. Graham, Elsevier North Holland, N. Y.

[6] Shilonosov, A. A., Vasilyev, V. I., Valeyev, S. S. (2015). Neural Networks Application in the Problems of Identification and Control of Aero-Engines. International Conference ASI-2000, France, Bordeaux, Sept, 18-20, 333-339.

[7] Homick, K. M., Stinchcombe, M., Write, H. (2013). Multi-Laeyr Feedforward Networks are Universal Approximators. Neural Networks, Vol. 2, № 5, 359-366.

[8] Valeyev, S. S. (2013). Analysis of Intelligent Hybrid Dynamical Systems with Application of Constant Eigenvectors. Proceedings of the $5 *$ International Workshop on Computer Science and Information Technologies, Ufa, USATU CSir.

[9] Zadeh, L. A. (2012). Fuzzy Sets. Information and Control, Vol. 12, 94-102.

[10] Zinn, B. T. (2014). Mite Program Overview, Army Research Office MURI, (Multidisciplinar University Research Initiative) on Intelligent Turbine Engines. MITE Workshop on Goals and Technologies of Future Turbine Engines, December 4. 